\title{
Ability of Mitscherlich-Spillman model to estimate critical soil phosphate levels
}

\author{
Anatoliy V. Pukhovskiy \\ Moscow State University of Environmental Engineering, Moscow, Russian Federation \\ Email address: \\ pukhows-cinao@mail.ru (A. V. Pukhovskiy)
}

\section{To cite this article:}

Anatoliy V. Pukhovskiy. Ability of Mitscherlich-Spillman Model to Estimate Critical Soil Phosphate Levels. International Journal of Nutrition and Food Sciences. Vol. 2, No. 2, 2013, pp. 45-51. doi: 10.11648/j.ijnfs.20130202.14

\begin{abstract}
More than 150 years research groups from different countries have been studying the effect of various factors on the productivity of the plants described by so-called productivity functions (PF). Interest to PF stems from the needs of economists, agronomists, agricultural chemists and environmentalists who use the PF modeling as a basis for solving their problems. The article describes development of models of productivity for agricultural chemistry and approaches to its calibration. The phenomenon of quasi-linearity $\left(\mathrm{R}^{2}>0.998\right)$ of Mitscherlich-Von Boguslawski functions within the range of 30 to $90 \%$ efficiency after logarithmic transformation of the argument and practical applications of the method were considered. The limitations were considered in the use of recommendations in relation to the properties of the scale of the studied factors. The approach proposed is applicable to only the values belonging to an absolute scale (ratio scale). The analysis of the possibility and feasibility to assess the so called critical levels of mobile phosphates was made using modeling with recently published Rothamsted long-term experimental data.
\end{abstract}

Keywords: Function Of Productivity, Modeling, Model Selection, Available Phosphate

\section{Introduction}

A large number of factors (light, temperature, availability of water, nutrients, etc.) influences the plant productivity complicating the detailed understanding. More than 150 years research groups from different countries have been conducting pilot studies and try to find the best ways to describe the effect of these factors on the productivity of the plants - so-called productivity functions (PF). Interest in productivity functions is versatile; they are needed by economists, agronomists, agricultural chemists and environmentalists as a basis for solving their problems with the use of modeling. Approach to defining the productivity functions evolves with accumulation of knowledge, ideas, tools and requirements. The priority work on the productivity functions in agricultural chemistry is the work of Liebig, 1855 [1], although so-called model of Liebig (FPL) in the linear and partially smoothed form, took the mathematical form of a linear function with a subsequent plateau later [2-6 etc.]. Beginning in 1909, the works of Mitscherlich [7] and independently from 1923 works of Spillman [8] offered a model (productivity functions of Mitscherlich-Spillman PFMS) based on the inverse exponent, which has also a plateau as productivity function of Liebig, but it has damped response within the break point. Further development of theoretical concepts of the FP was made by Baule in 1918 (multifactor model of Mitscherlich-Baule [9]), Bray since 1944 (the concept of influence of mobility of food compounds on PF [10-12], Von Boguslawski E., \& B. Schneider, refinement of Mitscherlich model [13-16] and many other researchers [2-4, 17-29]. It is necessary to recognize the technical complexity of calibration of PFMS, especially for two or more variables. That is why, from the mid-twentieth century, methods and approaches to the modeling of PF on the basis of empirical regression models developed intensively [28]. However, analyzing publications one can notice a strong interest in classical FPL and FPMS models and in modifications based on them. It should be noted that in 1895 Liebscher [30] proposed a theory that can now be seen as an early synthesis of concepts (models) of Liebig and Mitscherlich. In 1971, Greenwood et al. [26] using the well known chemical kinetics function of Michaelis-Menten [31] presented a new formalization of Liebscher ideas, further developed in later publicatins [32]. In earlier studies [7, 10, 11, etc.] because of the complexity in data obtaining and processing, PF related mainly to the effect of one factor (nitrogen, phosphate, potassium). However, taking into consideration the com- 
plex character of the influence of factors on yield, PF with two or more such relatively dynamic factors, e.g. combination of water and nitrogen fertilizer [24-26] draw our attention. In this paper, the main focus is on the factor of phosphorus. Phosphorus compounds are often one of the limiting factors in plant productivity $[1,7,13,33]$. Their low mobility in soil determines prolonged aftereffect of phosphate fertilizers, which allows them to "store" [12, 34]. Increase in the phosphate content in the soil using phosphate fertilizers increases the efficiency of the use of other fertilizers, especially nitrogen [7, 33-35]. However, on sloping lands it also increases the risk of run-off into waterways, leading to eutrophication [6, 36-41]. The second important aspect of the use of phosphate fertilizers is their high price compared to other types of fertilizers. Thus, both economic and environmental factors contribute to the optimal use of phosphate fertilizers limiting doses to the point when the soil reaches the so-called critical level (CL) beyond which additional phosphorus fertilization doesn't significantly increase the productivity, is not economically feasible or environmentally unacceptable [39]. Recently published works of researchers from Rothamsted contain data with long-term studies of the effect of residual soil phosphate (by Olsen) on the productivity of spring barley, winter wheat in three contrasting type soils, and an assessment of critical level based on the model PFMS [42-44]. However, it was considerable uncertainty (up to 5-8 times in the phosphates CL by years), which caused the need for additional investigation of the possible causes of published fluctuations.

One of the approximate methods to determine CL according to agronomic criteria was proposed by Cate and Nelson [19]). Availability of model FP formally simplifies determination of CL, but the accuracy of its estimation is still low and depends largely on the chosen criteria, the quality of the source data and the type of FP. Comparison of several types of the most important FP for an assessment of CL and development of practical recommendations is the main purpose of this work. In [34,35, 45-48] we have considered various PFs. In [45] main FPs and their development are discussed. Further review and bibliography on this subject can be found in [2-6, 36, 49] and recently published works [27, 32].

\section{Methods and Objects of Research}

\subsection{Data}

The main research method (as in the previous studies $[34,35,45-48])$ is PF modeling based on the previously published data from field experiments on the effects of agrochemical factors on productivity of field crops with the use of Microsoft Excel.

The study uses the recently published works of researchers from Rothamsted which contains data of long-term studies of the effect of residual soil phosphate (by Olsen) on the productivity of spring barley [42-44].

\subsection{Details of Logarithmic Approach}

In recent work, most researchers give preference to theoretically based models of PF, primarily PFL, PFMS and their modifications. However, taking into consideration the complexity of the direct calibration of such PF even in a single factor case, for practical purposes we proposed a new calibration method based on a logarithmic transformation of the data [45]. To illustrate this approach (table 1), the results of model analysis are presented for different values of variable $\mathrm{X}$, and the transformed variable $(\lg (\mathrm{X}))$ and calculated PF (fig.1 and fig. 2) in accordance with equations (1) and (2):

PFMS as assumed in [7]

$$
\mathrm{Y} / \mathrm{Y}_{0}=1-\exp (-\mathrm{a} \mathrm{X})
$$

Where Y- yield, Yo - maximal yield, $\mathrm{a}=1$

PFMSB as assumed in [45]

$$
\left.\mathrm{Y} / \mathrm{Y}_{\mathrm{o}}=\exp \left(-(\operatorname{lgX}-0.68)^{2} / 2 \sigma^{2}\right)\right)
$$

Where $\sigma^{2}=1$.

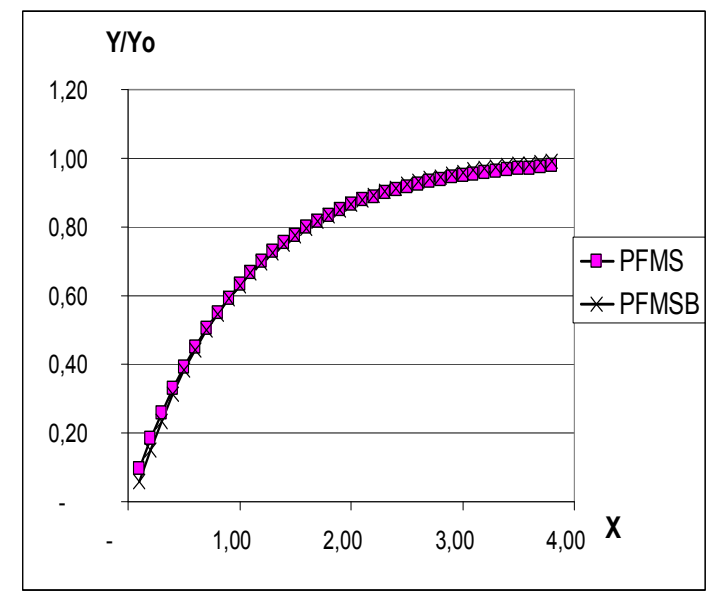

Figure 1. Graphics of PFMS and PFMSB, depending on the disposal variable of $X$.

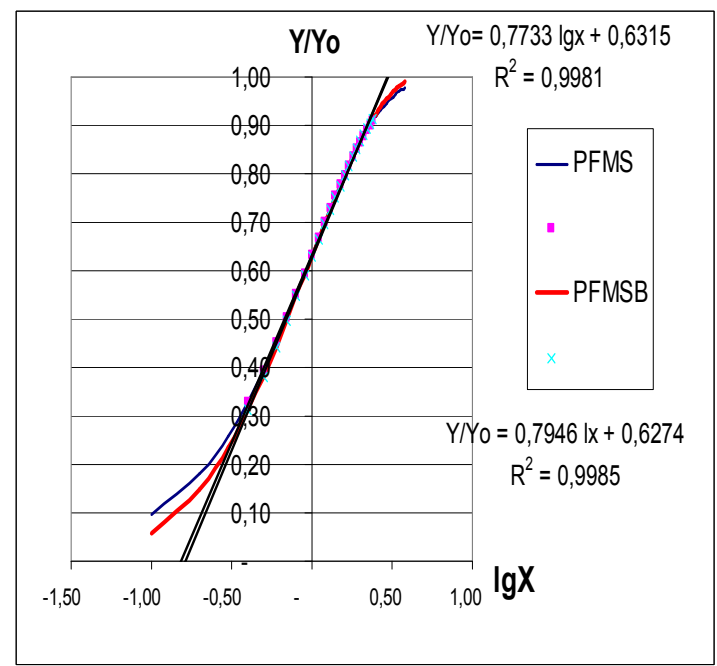

Figure 2. Graphics of PFMS and PFMSB, depending on the value of $\lg X$. 
In the traditional format (figure 1) PFMS and PFMSB graphics practically merge, both of these functions being nonlinear, which causes the problem of the direct calibration. With logarithmically transformed argument (figure 2), plots of PFMS and PFMSB functions in the $Y / Y_{0}$ range from 0,3 to 0,9 have quasi-linear sections that are practically identical to the parameters of models. It should be noted that $Y / Y_{0}$ range from 0,3 to 1,0 is the most agronomically important, i.e. most experimental data do not go beyond those limits. The interval from 0,3 to 0,9 is described adequately by a linear function of log-transformed argument, which can be easily calibrated and one can restore the original model for an adequate prognosis for out of range of the linear approximation through its parameters [45].

\subsection{Calculations with Rothamsted LONG-TERM FIELD EXPERIMENT}

Table 1 and figures 3-4 shows a comparison of the experimental data obtained in field tests in Rothamsted [42-44] with the results of PF modeling.

Table 1. Experimental data on the dependence of the average production of winter barley on the content of labile phosphates and their comparison them with the results of different PF modeling (abbreviations see in fig. 3 and 4).

\begin{tabular}{|c|c|c|c|c|c|c|c|}
\hline \multirow{2}{*}{$\begin{array}{l}\text { Content of } \\
\text { labile phosphates } \\
\text { (according to } \\
\text { Olsen), } \mathrm{mg} / \mathrm{kg}\end{array}$} & \multirow{2}{*}{$\begin{array}{l}\text { Average } \\
\text { production, } \\
\text { t/ha }\end{array}$} & \multicolumn{6}{|c|}{ Results of modeling of function (model) of productivity } \\
\hline & & PFL & PFC & PFLM & PFMS & PFSB & PFLC \\
\hline 2 & 2 & 2,32 & 2,68 & 2,14 & 1,89 & 2,15 & 1,79 \\
\hline 3 & 2,26 & 2,62 & 2,88 & 2,67 & 2,54 & 2,72 & 2,65 \\
\hline 4 & 3,3 & 2,92 & 3,07 & 3,05 & 3,04 & 3,13 & 3,18 \\
\hline 5 & 3,47 & 3,22 & 3,26 & 3,34 & 3,43 & 3,45 & 3,53 \\
\hline 7 & 3,85 & 3,81 & 3,60 & 3,78 & 3,97 & 3,90 & 3,99 \\
\hline 7 & 4,28 & 3,81 & 3,60 & 3,78 & 3,97 & 3,90 & 3,99 \\
\hline 10 & 4,25 & 4,71 & 4,04 & 4,25 & 4,41 & 4,32 & 4,36 \\
\hline 13 & 4,76 & 4,81 & 4,41 & 4,59 & 4,62 & 4,56 & 4,57 \\
\hline 14 & 4,79 & 4,81 & 4,52 & 4,69 & 4,66 & 4,62 & 4,62 \\
\hline 14 & 4,62 & 4,81 & 4,52 & 4,69 & 4,66 & 4,62 & 4,62 \\
\hline 15 & 4,46 & 4,81 & 4,61 & 4,78 & 4,69 & 4,67 & 4,66 \\
\hline 16 & 4,57 & 4,81 & 4,70 & 4,81 & 4,72 & 4,71 & 4,69 \\
\hline 17 & 4,75 & 4,81 & 4,78 & 4,81 & 4,74 & 4,75 & 4,72 \\
\hline 22 & 4,71 & 4,81 & 5,04 & 4,81 & 4,79 & 4,86 & 4,80 \\
\hline 23 & 4,91 & 4,81 & 5,06 & 4,81 & 4,79 & 4,87 & 4,81 \\
\hline 26 & 4,82 & 4,81 & 5,09 & 4,81 & 4,80 & 4,89 & 4,83 \\
\hline 27 & 4,92 & 4,81 & 5,08 & 4,81 & 4,80 & 4,89 & 4,83 \\
\hline 30 & 4,84 & 4,81 & 5,00 & 4,81 & 4,80 & 4,89 & 4,83 \\
\hline 35 & 4,75 & 4,81 & 4,68 & 4,81 & 4,81 & 4,86 & 4,81 \\
\hline 38 & 4,76 & 4,81 & 4,39 & 4,81 & 4,81 & 4,84 & 4,79 \\
\hline \multicolumn{2}{|l|}{$\mathbf{R}^{2}=$} & 0,923 & $\mathbf{0 , 8 4 7}$ & 0,945 & 0,968 & 0,960 & 0,965 \\
\hline \multicolumn{2}{|l|}{$\mathbf{S}=$} & 0,25 & 0,35 & 0,21 & 0,16 & 0,18 & 0,16 \\
\hline
\end{tabular}




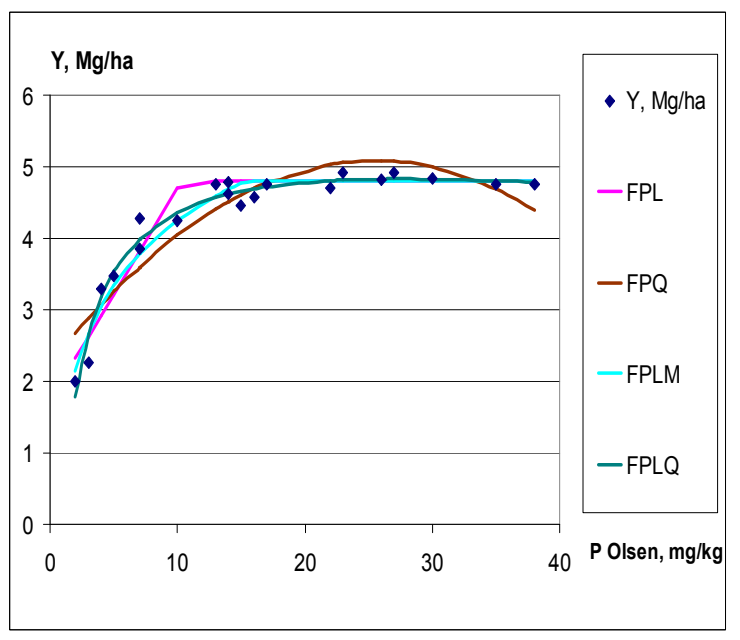

Figure 3. Comparison of experimental data (exp) with PFL (linear function with a plateau, PF of Liebig), CPF (empirical quadratic model), PFLM (PF of Liebig modified by the author, a linear approximation of the argument in logarithmic form with the plateau), PFLC (logarithmic quadratic $P F, \quad$ empirical quadratic model of In-transformed arguments)e.

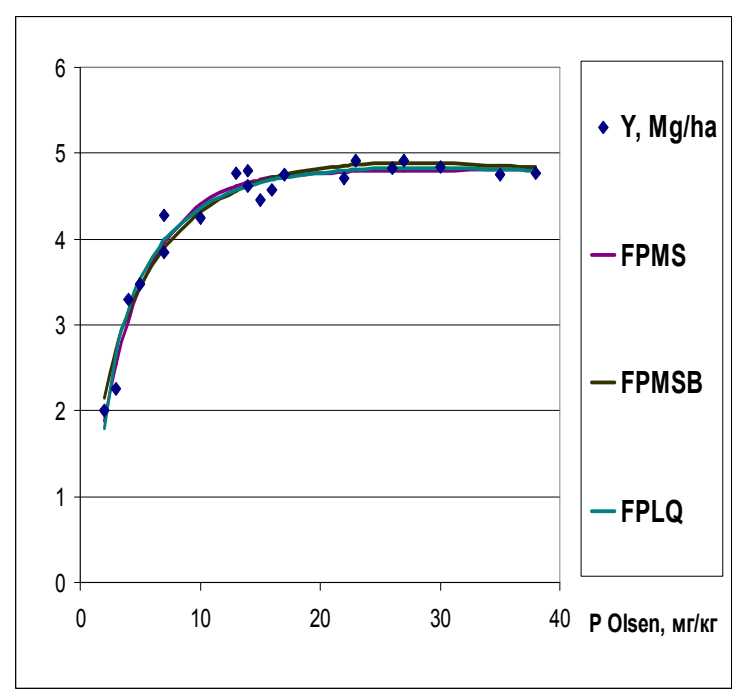

Figure 4 Comparison of experimental data (exp) with PFMS (PF of Mitscherlich -Spillman), PFMSB (PF of Mitscherlich -Spillmana modified Boguslawski [45]), PFLK (empirical quadratic model of log-transformed argument).

\section{Discussion}

The adequacy of the model PF can be estimated by conventional statistical criteria $\mathrm{S}$ (standard deviation) and $\mathrm{R}^{2}$ (coefficient of determination) [25].

According to these criteria, in this example PFMS showed the highest correlation (table 1 and figures 3, 4), followed in descending order by PFLC, PFMSB (this models in figure 4 practically coincide), then PFLM, PFL, PFC (worst value). The high efficiency of the empirical PFLK and PFLM (with log-transformed argument) should be also noted. It confirms the feasibility of ln-transformation of the argument (restrictions will be discussed below) and proba- bly high value of these models in critical conditions assessment. As it was mentioned above, evaluation of critical conditions is not absolute. Depending on the selected model of PF and criteria, the results of this evaluation may bear various level of uncertainty. For example, with seemingly right choice of the most adequate PFMS for data in the table 1, uncertainty of critical conditions in [42-44] proved to be unexpectedly high. Analyzing the situation, the author found that in addition to the agronomic explanation proposed in [42-44], two statistical factors could play a certain role. The first factor is the choice of high approximation to maximum productivity $\left(Y / Y_{0}=0.98\right)$, which requires the accuracy virtually unattainable in field experiments, as $Y_{0}$ is estimated with a rather large uncertainty. In earlier studies (e.g. [19]), more realistic value of $Y / Y_{0}=0.90$ was proposed.

The second factor is the asymptotic approach of the PFMS derivative to zero near the selected point. This, along with the flat (undefined) maximum of PFMS statistically determines the high uncertainty of critical conditions (figure 5). The lines show the intersection with curves at $Y / Y 0=0.9$ and $Y / Y O=0.98$. In this respect, the use of PFL and PFLM (with a much higher value of the derivative prior to the plateau compared to PFMS) appears to be more correct from a practical point of view to reduce the estimation uncertainty to an acceptable level.

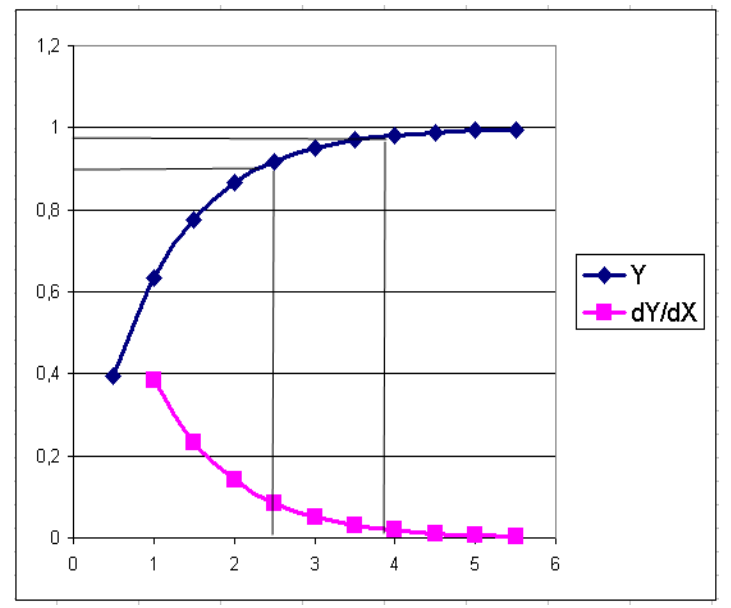

Figure 5 The integral and differential forms of PFMS.

At the same time in order to select the PF one should take into account that the calculated value of critical conditions can be more precise for selected significance level (if it is approaching the plateau), but less correct (in terms of the standard ISO 5725). This situation is to be expected for PFL, and is less likely for PFLM, given the significantly different levels of adequacy for this models in the example (table 1). Residual incorrectness of PFLM is less significant for properly selected level $Y / Y_{0}$. For example (table 1 and figure 5), the level of accuracy in the evaluation of critical conditions at $Y / Y_{0}=0.90$ (which, in our opinion, is more realistic than the $Y / Y_{0}=0.98$, taking into account environ- 
mental constraints) for PFMS and linear-logarithmic approximation would be almost the same both in terms of precision and accuracy. As to the estimation of critical conditions it should be noted that in the agronomy it is almost impossible to receive precision critical conditions at $Y / Y_{0}=$ 0.98. The reason for this for PFMS was discussed above. If we consider the problem within the framework of PFMSB or its empirical approximation of PFLK, according to [46], the maximum of the curve of maximum productivity increases with an increasing of rates of other nutrients. This phenomenon is seen in other studies, for example [33]. Rather, speaking of the critical conditions under present circumstances, the priority in their evaluation should be given to the most restrictive economic and environmental constraints [37, 38, 39, 40].

Concluding remark concerns the possibility and advisability of using the logarithmic argument in the PF. While employing the method of "boundary curve", Sumner in [50] used the logarithmic scale of the argument. It resulted in a more symmetric representation of PF. A similar phenomenon has been shown in [14-16, 46]. As it was shown in [34, $35,47,48]$, logarithmic scaling the argument is a very effective and powerful method (but rarely used by agrarian scientists), provided that the argument is an adequate physical quantity in describing the acting factor of PF. This physical quantity is measured on absolute scale (the so-called ratio scale). Then the logarithmic transformation is meaningful, unambiguous, and highly efficient [47]. However, very often the dose of fertilizer is an argument of $\mathrm{PF}$ in field experiments. This dose is superimposed on the background of mineral nutrition. The direct logarithmic transformation in this case would be incorrect, and bringing these two components to a common denominator is not always easily achievable. Some factors, such as in-soil and introduced nitrates can add up quite well removing this uncertainty. However, similar factors will often disagree on a quantity level. For example, the content of soil phosphate, determined by the chemical method, will not agree with doses of phosphorus fertilization on the scales used, and therefore can not be simply added without additional assumptions or appropriate calibrations.

\section{Conclusion}

Agronomic constraints for the phosphates are not well defined. This does not allow accurate evaluating the critical conditions. For this reason, while evaluating the $\mathrm{CE}$, one should most probably choose the most stringent economic or environmental restriction.

Correct logarithmic transformation of the argument is an effective technique in PF modeling.

The correctness of the logarithmic transformation of the argument is determined by the scale and is limited by the values measured in the ratio scale.

\section{Acknowledgements}

The author is grateful to colleagues from Rothamsted Research, especially Dr. P.R. Poulton, for kindly providing materials and a discussion of the main issues of this work, and to the referee Professor N.F. Khokhlov for critical commentst, and to Dr. Yu.Kolomiiskiy for reading and correcting of the manuscript.

\section{References}

[1] J. Von Liebig, "Die Grundsätze der Agrikulturchemie, mit Rücksicht auf die in England angestellten Untersuchungen," Vieweg, Braunschweig, 1855, p. 107 cited in Yu. Liebig Chemistry in the application to agriculture and physiology . Moscow; Leningrad, 1936. P. 5-36 (in Russian).

[2] C. Ackello-Ogutu, Q. Paris, and W. A. Williams, "Testing a von Licbig Crop Response Funciion against Polynomial Specifications," Amer. J. Agr. Econ, 1985. Vol. 67, pp. 873-80.

[3] R. L. Anderson, and L. A. Nelson, "A family of models involving intersecting straight lines and concomitant experimental designs useful in evaluating response fertilizer nutrients," Biometrics, 1975, vol.31, pp. 303-318.

[4] P. Berck, and G. Helfand, "Reconciling the von Liebig and Differentiable Crop Production Functions," American Journal of Agricultural Economics, 1990, vol.72, pp. 985-996.

[5] D. J.Greenwood, J. T. Wood, T. J. Cleaver, and J. Hunt, "A theory for fertilizer response," Journal of Agricultural Science, Cambridge, 1971, vol. 77, pp. 511-523.

[6] T. K. Hartz, and P. R. Johnstone, "Relationship between Soil Phosphorus Availability and Phosphorus Loss Potential in Runoff and Drainage," Communications in Soil Science and Plant Analysis, 2006,Vol. 37, Issue 11-12, pp. 1525-1536.

[7] E. A. Mitscherlich, "The law of the minimum and the law of diminishing soil productivity," (In German). Landwirtschafliche Jahrbuecher , 1909, 38, pp. 537-552. E. A. Mitscherlich, "Soil science for agriculture and forestry," (In German). 2nd edition, Verlag Paul Parey, Berlin, 1913, pp.317 E. A. Mitscherlich, " Die Bestimmung des Düngerbedürfnisses des Bodens," Paul Parey, Berlin, 1924, pp. 100 citied in E.A. Mitscherlich, Soil Science / translation from German language E.N. Shkonde / under ed. F.V. Turchin. Moscow, 1957. 417 p. (in Russian).

[8] W. J. Spillman, "Application of the Law of Diminishing Returns to Some Fertilizer and Feed Data," Journal of Farm Economics, 1923, vol.5, pp. 36-52.

[9] B. Baule "Mitscherlich's law of physiological relations," Landwirtschafliche Jahrbuecher, 1917, vol.51, pp. 363-385. (In German).

[10] R. H. Bray, "Soil-plant relations. p. I. The quantitative relation of exchangeable $\mathrm{K}$ to crop yields and crop response to potash additions," Soil Sci., 1944, vol. 58, pp. 305-324.

[11] R. H. Bray, "Correlation of soil tests with crop response to added fertilizers and with fertilizer requirement," In Diagnostic techniques for soil and crops. H. B. Kitchen Ed. American Potash Institute, Washington, D. C. 1948, pp. 53-86.

[12] R. H. Bray, "A nutrient mobility concept of soil-plant rela- 
tionships," Soil Sci., 1954, vol.78, pp. 9-22.

[13] R. H. Bray, and L. T. Kurtz, "Determination of total organic, and available forms of phosphorus in soils," Soil Sci, vol.59, 1945, pp.39-45.

[14] V. E.Boguslawski and B. Schneider, "Die dritte Annaherung des Ertragsgesetzes. 1. Mitteilung,, Zeitschriftfuer Ackerund Pflanzenbau 114 (3), 1962, pp. 221-236.

[15] V. E. Boguslawski, and B. Schneider, „Die dritte Annaherung des Ertragsgesetzes. 2. Mitteilung," Zeitschrift fuer Acker- und Pflanzenbau 116 (2) ,1963, pp. 113-128.

[16] V. E. Boguslawski, and B. Schneider "Die dritte Annaherung des Ertragsgesetzes. 3. Mitteilung,"Zeitschrift fuer Acker- und Pflanzenbau 119, 1964, pp. 1-28.

[17] B. R. Bock, and F. J. Sikora, "Modified-Quadratic Plateau Model for Describing Plant Response to Fertilizer," Soil Sci. Soc. Amer. J., 1990, vol. 54, pp. 1784-1789.

[18] B. W. Brorsen, and F.G.C. Richter, "Experimental Designs for Estimating Plateau-Type Production Functions and Economically Optimal Input Levels," Journal of Productivity Analysis, 2011, pp. 35.

[19] R. B. Cate, and L. A. Nelson, "A simple statistical procedure for partitionin soil test correlation data into two classes," Soil Sci. Soc. Am. Proc., 1971, vol.35, pp.658-659.

[20] F. R. Cox, "Economic Phosphorus Fertilization Using a Linear Response and Plateau Function," Comm. Soil Sci. Plant Anal., 1996, vol.27, pp. 531-43.

[21] F. R. Cox, "Range in Soil Phosphorus Critical Levels with Time”, Soil Sci. Soc. Amer. J., 1992, vol.56, pp. 1504-09.

[22] C. T. De Wit, and J. Goudriaan," Simulation of Ecological Processes," (2nd edition). Pudoc, Wageningen, 1978, 175 pp.

[23] C. T. De Wit, "Resource use efficiency in agriculture," Agricultural Systems ., 1992, vol. 40, pp. 125-151.

[24] M. D. Frank, B. R. Beattie, and M. E. Embleton, "A Comparison of Alternative Crop Response Models," American Journal of Agricultural Economics 1990, vol.72, pp. 597-603.

[25] S. S. Grimm, Q. Paris, and W. A. Williams, "A von Liebig Model for Water and Nitrogen Crop Response," Western Journal of Agricultural Economics, 1987, V. 12, No. 2, pp. 182-192.

[26] D. J.Greenwood, J. T. Wood, T. J. Cleaver, and J. Hunt, “A theory for fertilizer response," Journal of Agricultural Science, Cambridge, 1971, vol. 77, pp. 511-523.

[27] K. Harmsen, "A modified Mitscherlich equation for rainfed crop production in semi-arid areas. p. 1. Theory," Netherlands Journal of Agricultural Science, 2000, vol.48, pp. 237-250.

[28] R. W. Hexem, V. A. Sposito, and E. O. "Heady Applications of a Two-Variable Mitscherlich Function in the Analysis of Yield-Water-Fertilizer Relationships for Corn," Water Resour. Res., 1976, vol. 12 pp.6-I0.

[29] G. V. Johnson, "General-Model for Predicting Crop Response to Fertilizer,"Agron. J., 1991, Vol. 83. N. 2, pp 367-373.
[30] G. Liebscher, "Untersuchungen über die Bestimmung des Düngerbedürfnisses der Ackerboeden und Kulturpflanzen," Journal für Landwirtschaft, 1895, 43, pp. 49-216.

[31] L. Michaelis, and M. L. Menten, "Die Kinetik der Invertwirkung. Biochemische Zeitschrift," 1913, 49, pp. 337-369.

[32] G. O., Nijland, J.Schouls and J.Goudriaan "Integrating the production functions of Liebig, Michaelis-Menten, Mitscherlich and Liebscher into one system dynamics model," NJAS - Wageningen Journal of Life Sciences 2008. vol.55, No 2, pp. 199-224.

[33] Ivanova T.I. Results of use of increasing doses of mineral fertilizers in crop // Application of mathematical methods in agrochemistry research : Writings of All-Russian Institute of Fertilizers and Agropedology. Moscow, 1977. Iss. 56. pp. 15-51(in Russian).

[34] A.V. Pukhovskiy "Efficiency of phosphorus fertilizers taking into consideration their aftereffect" Melioration and water management (Melioraciya I vodnoe khoziaistvo)/ Moscow. 2011. No. 3. P. 12-14 (in Russian).

[35] Pukhovskiy A.V. "Methodic of evaluation of fertilizers and chemical meliorants payback" Agrochemical bulletin (Agrokhimicheskiy Vestnik). Moscow. 2010. No. 1. P. 35-40(in Russian).

[36] A. E. Johnston "Efficient Use of Nutrients in Agricultural Production Systems," Commun. Soil sci. Plant anal., 2000; vol.31, No11-14, pp. 1599-1620.

[37] L. Jordan-Meille, G. H. Rubæk, P. A. I. Ehlert, V. Genot, G. Hofman, K. Goulding, J. Recknagel Provolo G., and P. Barraclough "An overview of fertilizer $\mathrm{P}$ recommendations in Europe. p. soil testing, calibration and fertilizer recommendations," Soil Use and Management, 2012.Vol. 28, Issue 4, pp. 419-435.

[38] P. J. A. Kleinman, R. B. Bryant, W. S. Reid, A. N. Sharpley, and D. Pimentel, "Using soil phosphorus behavior to identify environmental thresholds," Soil Science, 2000, vol.165, pp.943-950.

[39] P. A. Matson, R. Naylor, I. Ortiz-Monasterio, "Integration of Environmental, Agronomic, and Economic Aspects of Fertilizer Management," Science, 1998.vol. 280, pp.112-115.

[40] R. W. McDowell, and A. N. Sharpley "Approximating phosphorus release from soils to surface runoff and subsurface drainage," J. Environ. Qual. 2001,vol. 30, pp.508-520. http./www.ars.usda.gov/SP2UserFiles/Place/19020000/Phos phorousPubs/JEQ30p508.pdf.

[41] R. Mcdowell, A. Sharpley, P. Brookes, and P. Poulton "Relationship Between Soil Test Phosphorus and Phosphorus Release to Solution," Soil sci. 2001; vol. 166, No 2, pp. 137-149.

[42] A. E. Johnston, and P. R.Poulton "Response of cereals to soil and fertilizer phosphorus," HGCA Research Review, No. 74, Rothamsted Research, Harpenden, 2011, 54 pp.

[43] A. E. Johnston, and P. R. Poulton, "Plant available soil phosphorus. Part I. p. the response of winter wheat and spring barley to Olsen P on a silty clay loam," Soil Use and Management, 2012, Wiley Online Library.

[44] A. E. Johnston, and P. R. Poulton, "Plant available soil phosphorus. Part II. p. the response of arable crops to Olsen 
P on a sandy clay loam and a silty clay loam ," Soil Use and Management, 2012, Wiley Online Library.

[45] A.V. Pukhovskiy, N.F. Khokhlov, "Method of approximation and calibrating of the model of Mitscherlich - Spillman - Baule - Boguslawski Russian Agricultural Sciences. February 2011, Vol. 37, Is. 1, pp 46-50 Original Russian Text (C) A.V. Pukhovskii, N.F. Khokhlov, 2011, published in Doklady Rossiiskoi Akademii Sel'skokhozyaistvennykh Nauk, 2011, No. 1, pp. 31-34. (in Russian).

[46] A.V. Pukhovskiy, A.V. Efremov, T.Yu. Pukhovskaya "About the method of boundary curve in "coordinate" agriculture," Fertility (Plodorodie). 2004. No. 3. P. 25(in Russian).

[47] A.V.Pukhovskiy, "Peculiarities of statistical manipulations of results of agrochemical research," Agrochemistry (Agrokhimia). 2001. No. 9. P. 66-74 (in Russian).
[48] A.V. Pukhovskiy, Multielements extragent and metods of agrochemical survey: conceptions, principles and prospects. - Moscow, 2003. - 102 p (in Russian).

[49] "Status and Methods of Research in Economic and Agronomic Aspects of Fertilizer Response and Use," Publication 918, National Academy of Sciences-National Research Council, 1961, $89 \mathrm{p}$.

[50] M. E. Sumner, "Field Experimentation: Changing to Meet Current and Future Needs," Soil Testing: Sampling, Correlation, Calibration, and Interpretation. /Ed. Brown J. R SSSA Special Publication Number 21 Soil Science Society of America, Inc. Madison, Wisconsin, USA, 1987, pp.119-132. 